\title{
OSCURAUIT SOL: STONE ENGRAVINGS AND OTHER CONTEMPORARY SPANISH RECORDS FOR THE A.D.1239 AND A.D.1354 ECLIPSES AND THEIR ASTRONOMICAL IMPLICATIONS
}

\begin{abstract}
The eclipse of A.D. 1239 June 3 was observed at no less than ten sites in Europe, but the one from A.D.1354 September 17 was observed only from two European sites. In this paper, we present several new references for the A.D.1239 and A.D.1354 solar eclipses, most of them from unpublished Spanish documents. In particular, we study three records engraved on stones whose existence was not known until recently. Such records are very rare in the rest of Europe. The study of ancient eclipses has proven to be useful for obtaining some astronomical data of interest to modern astronomy. In particular, the analysis of these eclipses may be useful for determining a range of $\Delta \mathrm{T}$ for the epochs.
\end{abstract}

Keywords: Ancient Eclipses, Medieval Spanish Astronomy, Deceleration of Earth

\section{Introduction}

Total eclipses of the Sun and Moon, as well as those partial eclipses in which one of the two bodies is largely hidden, are spectacular enough to be perceived by the naked eye. Furthermore, in times when science was not developed and the only explanation for these phenomena was the will of the gods, these events were often viewed as omens of good or bad fortune, reinforcements of recent decisions, or ominous signs of future happenings. Even today, when these phenomena are well explained, they continue to raise great expectations. For this reason, numerous records of solar eclipses are found throughout history, from the first and second millennium B.C., up to the present day.

In the Iberian Peninsula there are very few accounts of solar eclipses, (possibly because there are only a few researchers who focus their search on local sources), with the exception of the ones found in the main chronicles or scientific treatises. However, recent efforts are slowly increasing the number of new reports, mostly from local chronicles and annals written in vernacular languages.

In this paper, we present several new Spanish references for the A.D.1239 and A.D.1354 solar eclipses. In particular, we study three records engraved on stones whose existence was not known until recently. Such accounts are very rare in the rest of Europe. As far as we know, the only case is the one from Marola recorded by Stephenson ${ }^{1}$ for the A.D.1239 solar eclipse. Hence the importance of the three stone records discussed in this paper.

In addition to their historical interest, the study of ancient eclipses can be useful for obtaining some astronomical data. It is a well known fact that the rate of rotation of the Earth is slowly decreasing in time. There are many possible reasons for this fact, including internal and external mechanisms. The most important external causes are lunar and solar tides. The internal causes are very assorted: changing wind patterns, electromagnetic coupling between the fluid core of the Earth and the lower mantle are examples of short-term effects, while sea-level fluctuations associated with climatic variations are an example of a long-term effect. In any case, the most important one is the tidal friction.

Since Universal Time (UT) is a time scale based on the rotation of the Earth and $\Delta \mathrm{T}$ is defined as the difference between the uniform time scale (Dynamical Time), and Universal Time (related to the rotation of the Earth), it is 
clear that $\Delta \mathrm{T}$ varies over time. The problem is that this value does not change uniformly. This means that it is not possible to predict exact values for $\Delta \mathrm{T}$, which leaves as the only possibility its deduction a posteriori from observations.

The value of $\Delta \mathrm{T}$ is strongly related to occultations and eclipses because it is used not only for the calculation of the exact times of an eclipse or occultation, but also for determining the position of the central line and the zone of visibility. A value $\Delta \mathrm{T}=3600 \mathrm{~s}$ is roughly equivalent to a shift of $15^{\circ}$ in longitude.

Since, as previously stated, past $\Delta \mathrm{T}$ values can be deduced from historical astronomical observations, it is of interest to compile and study new sources. Ancient eclipses have been widely studied, specially by F. R. Stephenson, for example in Morrison and Stephenson ${ }^{2}$, and Stephenson ${ }^{3}$ following and enlarging the works of J. K. Fotheringham (with several papers in the beginning of the $20^{\text {th }}$ century, see, for example the one from $1935^{4}$ ) and R. R. Newton ${ }^{5}$, among others.

In general, the derived error in $\Delta \mathrm{T}$ obtained from ancient eclipses is quite large, mainly due to the large width of the totality zone and the usual imprecision in the definition of the observational place or time. One option for partially solving these problems is the analysis of total eclipse records observed from multiple sites, which could provide a narrower parameter range.

In addition, several authors have considered the possibility of using these observations to improve other astronomical parameters: in their papers Tanikawa et al. ${ }^{6,7}$ have used observations of ancient eclipses for the simultaneous determination of $\Delta \mathrm{T}$ and the variation of the tidal acceleration of the lunar motion $\Delta \dot{n}$. This study is out of the scope of this paper.

Summing up, in this paper we present several previously unnoticed reports of the A.D.1239 and A.D.1354 eclipses. We focus our attention especially on three reports carved in stone from two Spanish cities, but we present also other records obtained from local sources. These new observations are generally not complete in the sense that the totality of the eclipse cannot be fully assured from the texts, but in some cases totality can be asserted quite confidently. The records are important in the sense that they contribute new data to the astronomical literature. We analyze the new records individually, obtaining a range of values for $\Delta \mathrm{T}$ supposing totality and then different magnitudes for the eclipses. Then, we compare the values obtained from other places of observation.

The Sun ephemeris has been computed using DE406 theory ${ }^{8}$ and to compute the Moon position we take the ELP 2000-82B lunar theory ${ }^{9}$ using a value of $\dot{n}=-26^{\prime \prime} / c y^{2}$

\section{The A.D.1239 June 3 eclipse.}

Very few European records of solar eclipses are found in scientific treatises; instead, we find them mainly in chronicles or annals. When dealing with descriptions of European medieval eclipses, we must consider some issues regarding to the measure of time. For example, seasonal hours were commonly used in medieval times: the first hour followed sunrise and the seventh hour started at noon, but sometimes hours were counted from sunset or midnight. And there is also the possible use of different eras instead of Anno Domini. A discussion of general aspects of European eclipses has been published by Stephenson ${ }^{10}$, but in the particular case of Spanish medieval eclipses, we must also consider a local particularity: the word "Era" at the end of a paragraph refers to the Spanish era. In order to translate the date to Anno Domini, we must subtract 38 years from the given year. The Spanish era, Hispanic era or Caesar era refers to 
the dating system used in Hispania from the $3^{\text {rd }}$ to the 14th century, when the Anno Domini system was adopted. It began with year one in 38 B.C., probably the date of a new tax imposed by the Roman Republic on the population of Iberia related to the beginning of the Pax Romana in Hispania. The reason why it was so widely used in medieval Spain is not known.

The eclipse of A.D.1239 June 3 is one of the most recorded in the history. This is not amazing, because the path of totality crossed the South of Europe, including Portugal, Spain, France and Italy (See figure 3). Stephenson ${ }^{11}$ compiled and analyzed a large number of accounts from West Europe including Arezzo, Cesena, Coimbra, Florence, Montpellier, Marola, Siena and Split. Previously, Celoria $^{12}$ provided a survey of more than 30 observations that were analyzed and completed by R. R. Newton ${ }^{13}$ who also included observations from Britain.

We have searched in local Spanish sources that have gone unnoticed by scholars and we have found several additional reports. The first and most complete of them is an astronomical observation included in the Llibre dels Fets $^{14}$, which refers to the observation of the eclipse from the city of Montpellier. Other reports from Pamplona, S. Pedro de Cardeña and Perpignan are also included, but the most outstanding report comes from the city of Soria, in the form of two stone engravings.

It is worthwhile to mention that the A.D.1239 eclipse presents a difficult numerical analysis, in the sense that the boundary values obtained for $\Delta \mathrm{T}$ are very large, because the path of totality is fairly horizontal in almost all the observational sites. In this sense, the presence of new observational locations near the edge of totality could provide a better approximation for $\Delta \mathrm{T}$.

From figure 3 we can see that the path of totality of the eclipse clearly crossed Spain, which was, at that moment, divided into several Kingdoms. There is only one incomplete published record coming from this area, which we present as an example: Stephenson ${ }^{19}$ records a paragraph from the Anales Toledanos Segundos. The Anales Toledanos (Annals of Toledo) are a series of three old Spanish annals wrote mostly during the XIII ${ }^{\text {th }}$ century and covering the medieval history of the Kingdom of Toledo. The Anales Toledanos Segundos end in A.D. 1250 and they were probably the work of a mudéjar (descendent of the Muslim population that converted to Christianity before the threat of exile at the end of the $X^{\text {th }}$ century, after the fall of the Muslim kingdom of Granada), because a special interest in Andalusia Muslim affairs is shown throughout the work. The following text mentions the eclipse observed in Toledo:

The Sun was obscured on Friday at the 6th hour of the day, and it lasted for a while between the 6th and the 9th hours and it lost all its strength and there was as though night. There appeared many stars, and the Sun grew bright again of its own accord, but for a long time did not regain the strength that it usually has. Era 1277.

As previously stated, the word "Era" at the end of the paragraph refers to the Spanish era. In order to translate the date to the Anno Domini, we must subtract 38 years from 1277, in this way, we obtain the year A.D.1239.

If we use the value of $\Delta \mathrm{T}$ provided by Stephenson for the epoch, we can see that Toledo was very near (and out of the limits) of the edge of the shadow. Stephenson rejected this record, since he only assumes totality when the complete disappearance of the Sun is clearly described. He states: "Although the account relates that the Sun lost all its strength, this could simply mean that what remained 
of it could be viewed without dazzling the eyes- rather than necessary implying totality". However, the sentence "There appeared many stars" suggests that the eclipse, if not total, could have been nearly total. So, if we consider the possibility that the eclipse has a magnitude of 0.95 , we would obtain a range $900<\Delta \mathrm{T}<3600 \mathrm{~s}$; and for a magnitude of 0.99 the range would be $400<\Delta \mathrm{T}<2800 \mathrm{~s}$.

Let us consider now the particular record of the observation of the A.D.1239 eclipse seen in Montpellier. The most well-known is taken from the Anales de la corona de Aragon. Stephenson remarks that there is a similar account in Latin in the Indices Rerum ab Aragoniae Regibus Gestarum, however he misses another record, the one included in the Llibre dels Fets ${ }^{16}$ (chap. 305) of King Jaime I, making reference to the eclipse as seen from the city of Montpellier:

During my stay at Montpellier, the Count of Toulouse (...) came to see me. It was a year after the conquest of Valencia that I went to Montpellier. One Friday, between midday and nones, there was the greatest eclipse seen in the memory of men now living, because the moon covered the whole of the Sun, and one could see seven stars in the sky.

The Llibre dels Fets is a medieval chronicle written in vernacular language. It is considered the first of the four great chronicles of the Kingdom of Aragon. King Jaime I (1208-1276) himself describes his life and the conquest of the Kingdoms of Valencia (A.D.1238) and Mallorca (A.D.1229). Jaime I died in 1276 , so the original work must have been finished shortly before his death, but the oldest copy that has survived comes from the $\mathrm{XIV}^{\text {th }}$ century.

The record included in the Llibre dels Fets refers to the same observation as the one included in the Anales de la Corona de Aragon, however it is worthwhile to remark some details that are not included in this latter record. In the first place, there is a reference to the conquest of the city of Valencia. The king came into the city on 1238 October 9, only seven months (and not a year) before the facts. Secondly, the expression "many stars appeared" is present in other medieval records and it is commonly interpreted as an evidence of a large eclipse, not necessary total. The difference in this case is that the report clearly states totality, together with the presence of seven stars. The identification of the seven stars is, obviously, open to conjectures. According to Können ${ }^{17}$ during a total eclipse the limiting magnitude is +3.5 , so even the Pleiades cluster could have been one of these stars. An attempt to identify the stars could include Saturn, Mars, Sirius, Mercury, Betelgeuse, Rigel or Aldebaran. Jupiter was under the horizon at the time of the eclipse. Perhaps Venus should be included, replacing one of the stars, but it was very near to the Sun (See Table 1 for the position of the five main planets). The solar corona has a magnitude of -12 while the altitude of the Sun was $69^{\circ}$ and, in our opinion, this would reduce its visibility. However, Stephenson takes a different view regarding to this issue and taking as reference the only other known report of this eclipse where the presence of other celestial bodies is mentioned. This account comes from the Italian city of Arezzo and it was previously quoted by Celoria $^{18}$ :

(...) I saw the whole body of the Sun covered step by step and it became night. I saw Mercury close to the Sun (...)

Stephenson states that presumably the writer confused Mercury and Venus. 


\begin{tabular}{|c|c|c|c|c|c|c|c|c|c|c|}
\hline & \multicolumn{2}{|c|}{ Mercury } & \multicolumn{2}{c|}{ Venus } & \multicolumn{2}{c|}{ Mars } & \multicolumn{2}{c|}{ Jupiter } & \multicolumn{2}{c|}{ Saturn } \\
\hline Year & Mag. & Elon. & Mag. & Elon. & Mag. & Elon. & Mag. & Elon. & Mag. & Elon. \\
\hline 1239 & 1.25 & $20.56 \mathrm{E}$ & -3.9 & $1.10 \mathrm{E}$ & 0.7 & $85.7 \mathrm{~W}$ & -2.4 & $87.33 \mathrm{E}$ & 0.2 & $26.76 \mathrm{~W}$ \\
\hline 1354 & 2.46 & $10.70 \mathrm{~W}$ & -3.84 & $17.84 \mathrm{~W}$ & -0.3 & $94.3 \mathrm{~W}$ & -1.8 & $48.18 \mathrm{~W}$ & 0.0 & $98.12 \mathrm{E}$ \\
\hline
\end{tabular}

Table 1: Magnitudes and elongations of the five main planets on 3 June 1239 and on 17 September 1534. Even though for the latest of these dates there is no register that includes visibility of stars, we have included data for the main planets for information purposes.

If we carry out the computations using the accepted current astronomical data, in Montpellier the eclipse was total, with duration of $4.5 \mathrm{~m}$. The local time of maximum phase was 12:05. At this place, we obtained the preliminary value of $\Delta \mathrm{T}-6200<\Delta \mathrm{T}<1300 \mathrm{~s}$.

For the sake of completeness, we would like to remark another observation of this eclipse from a Spanish city quoted in the Iohannis Longi Chronica S. Bertini $^{19}$, written in the XIV ${ }^{\text {th }}$ century in the Benedictine French abbey of St. Omer and not commented by Celoria or Stephenson:

That year on 3 Nonas Iunii about midday an extraordinary Sun eclipse happened and especially in part of the Kingdom of Navarre and near Pamplona, up to the point that that day, which was previously clear, it became as dark as it was dark night. (...) And, therefore, an eclipse of the Moon, (...) should be universal; but not so the eclipse of the Sun, that is never universal.

The Nonas of June fell on the fifth day of this month, the day before was named Pridie Nonas Iunii and the previous was 3 Nonas Iunii, that is is the $3^{\text {rd }}$ of June. Using current data, the eclipse was total in Pamplona, but not in the whole Kingdom of Navarre, which included part of France at this time, hence the remark "in part of Kingdom of Navarre". From the quotation, totality in Pamplona cannot be asserted so we will not use this account for analysis of $\Delta \mathrm{T}$ but, assuming this totality, we would obtain a $\Delta \mathrm{T}<900$ s value.

Another local report comes from the Memorias Antiguas de Cardeña ${ }^{20}$ from the Monasterio de San Pedro de Cardeña (Cardeña henceforth), near Burgos (Spain):

Era of MCLXXVII years, III nones of June, at midday the Sun darkened and it was night and they see the starry sky.

For totality in Cardeña we obtain $-2500<\Delta \mathrm{T}<900$ and for a magnitude of 0.99 the range is $-3500<\Delta \mathrm{T}<1200$. There are other written primary sources that also mention this eclipse, such as the Anales Complutenses or Anales Castellanos Segundos, but we are not going to examine them because they do not add more information. Lastly, it is also worth noticing that the eclipse was also observed in Perpignan, as states a quotation in the Cronicó de Perpignan ${ }^{21}$ :

In the year 1239, in the month of June, on the first Friday, the Sun hid its rays.

Another observation not previously quoted was recorded twice in the city of Soria (Spain) ${ }^{22}$. In the Concatedral de San Pedro is written "OBSCVRATVS $\mathrm{E}$ (st) SOL(s)T(i)CIO IV", (see figure 1). Let us note that this report, in principle, 
has no use for astronomical purposes, at least until the discovery of another fragment in San Nicolas church (now in ruins) that we will consider later.

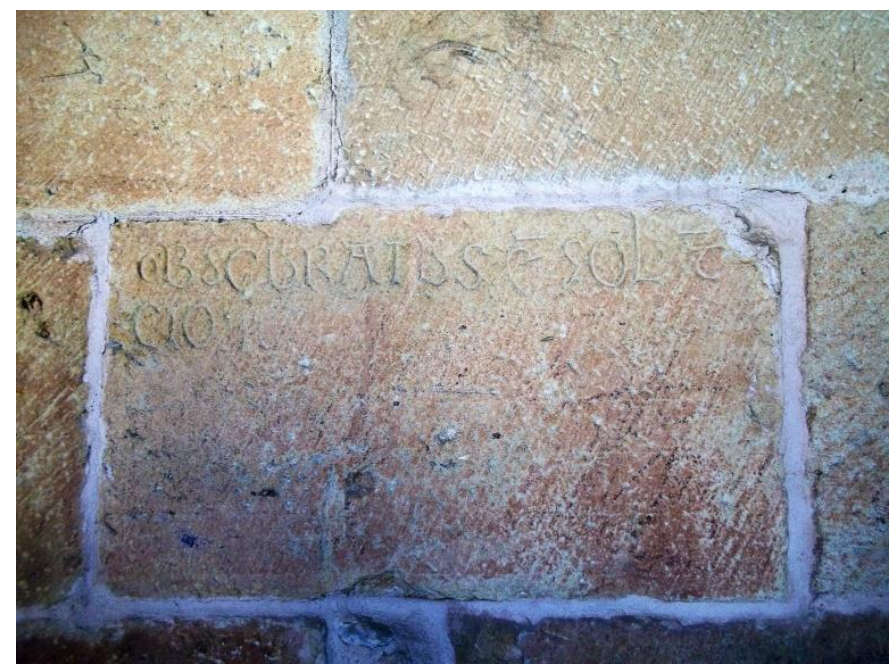

Figure 1: Inscription from the cloister of the Concatedral de San Pedro, in Soria.

The primitive San Pedro church surely had its origin during the repopulation of Soria (1109-1114), under Alfonso I. The date of a funeral inscription in the eastern wall has been used to date the cloister to 1205. The engraving in figure 1 is located in the northern wall of the cloister. The fragment is not complete, but the presence of the words "Obscuratus" and "Solis" led the scholars to a passage from the gospel of Saint Luke (23:44-45) about the death of Jesus: "And the Sun was darkened, and the veil of the temple was torn in half". The engraving of the cloister of San Pedro, therefore, could be just a memory of a Gospel passage linked to the death of Christ on the cross.

However, the finding of another engraving in the nearby church of San Nicolás, with a similar phrase: CVRAT(us) EST SOL(sticio, or more likely, solis) ER(a) MCXXLX(xvii) (See figure 2) made scholars suspect that the author was referring to a solar eclipse of which he was a witness. The origin of San Nicolás church is unknown. It is first mentioned in the census of 1270 entrusted by Alfonso X. The church was later abandoned and fell into ruins.

The fragment appeared during the cleaning and restoration work, in 1970 , in the remains of the tympanum of a doorway, probably the easternmost door of the south wall. The dimensions of the sandstone fragment preserved are $106 \mathrm{~cm}$ of maximum length, $15 \mathrm{~cm}$. of thickness and $32,5 \mathrm{~cm}$. of height. It is decorated by two poly-lobed arches with roses, with remains of a third arch. The inscription is enclosed in a band under the decoration. The late date provided by the inscription represents an approached limit to the completion of the temple. 


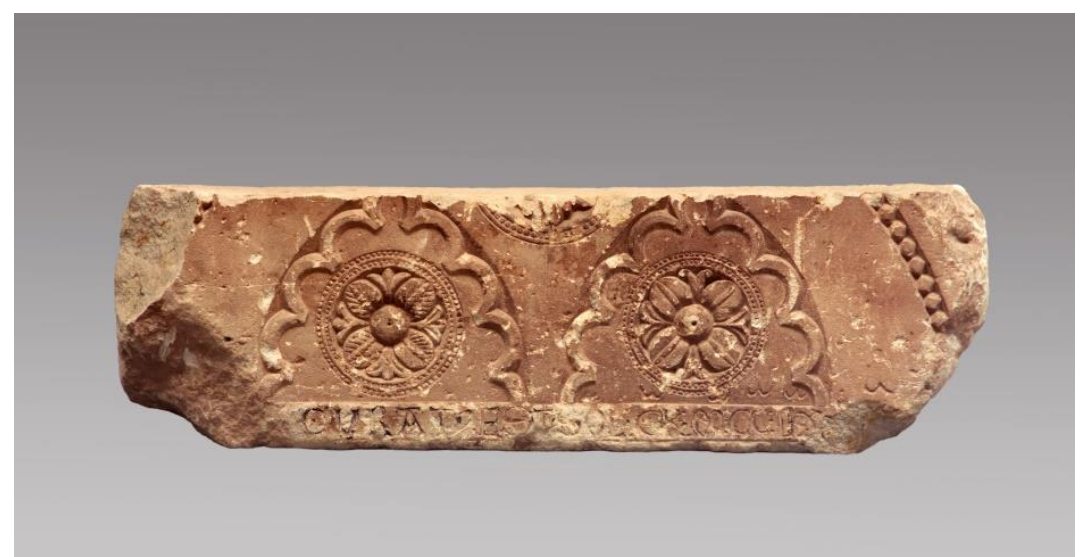

Figure 2: Sandstone fragment from St Nicholas church with the inscription "CVRAT(us) EST SOL(sticio, or more likely, solis) ER(a) MCCLX(xvii)" (Reproduced with the permission from the Museo Numantino of Soria)

Once again, the word "Era" appears, providing the data A.D.1239. Clearly, the eclipse was recorded in Soria, but totality is not evident from the text.

The duration of the eclipse in Soria using the current data was 6 min. The maximum of the eclipse was at 11:35 and the altitude of the Sun was $63^{\circ}$. The induced $\Delta \mathrm{T}$ range obtained for this site, assuming totality, is $-1100<\Delta \mathrm{T}<1600$ s. The assumption of totality will be discussed later.

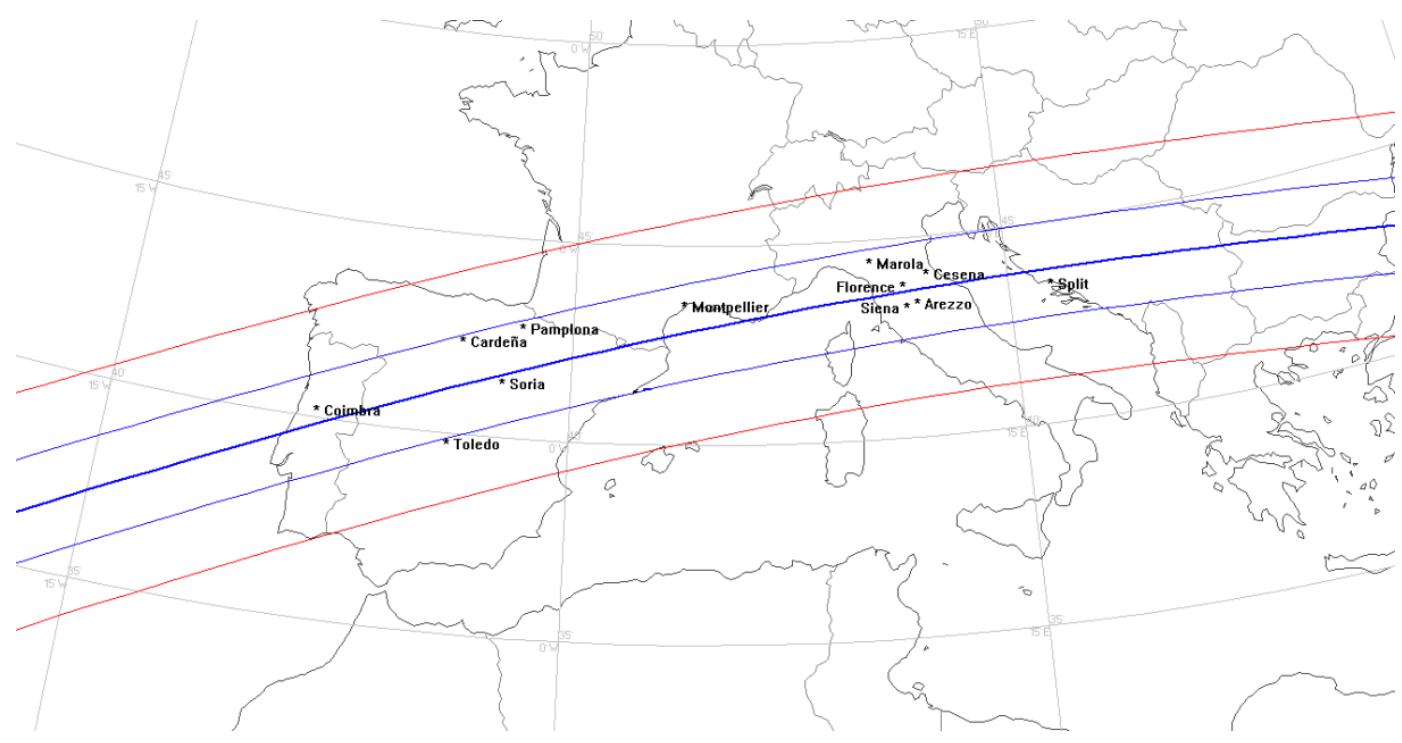

Figure 3: Path of totality for the eclipse of 3rd June 1239 (in blue). The red band corresponds to a magnitude of 0.99 (Using SkyMap Pro ${ }^{23}$ )

\section{The A.D.1354 September 17 eclipse.}

For this hybrid eclipse Stephenson ${ }^{24}$ records only one account in the city of Perugia, where the eclipse was partial although very large. This fact provides us boundaries of $\Delta \mathrm{T}: \Delta \mathrm{T}>4265 \mathrm{~s}$ or $\Delta \mathrm{T}<4140 \mathrm{~s}$. In his survey of solar eclipses, Ginzel $^{25}$ gives more references from Florence, Bologne and Rome. None of them are complete and even when in the Istorie Di Matteo Villani, Cittadino Fiorentino, Lib IV, C.XXIV the writer states that in Florence the Sun was almost totally covered; this does not provide further information.

From figure 6, we see that the narrow totality path crosses Spain, but there were no registers from this country about this eclipse until recently. In this paper we have included two new observations: firstly a quote from the Rubriques de 
Bruniquer $^{26}$ and secondly an observation from the city of Sos del Rey Catolico ${ }^{27}$ (Sos henceforth), in northern Spain. This second observation is carved in stone, making it one of the scarce European records of this kind of a solar eclipse.

Regarding the first account, Esteve Gilabert Bruniquer i Riera was a notary from Barcelona in the XVI-XVII ${ }^{\text {th }}$ century. In 1603 he was appointed sindic of the city and was given the task of making some annotations containing the dispositions, laws, privileges and dietaris (roughly speaking, a dietari is similar to a diary written by particulars or institutions. In this later case, political, economic or religious events were written down, but also remarkable phenomena could be reported). After his death this task was continued by other authors, but the work remained named after the first writer: Rubriques de Bruniquer.

We are interested in volume 5 where, under the title "Prodigious and awesome things," there are listed a survey of astronomical phenomena, among them the reference to this eclipse:

Wednesday 16th September 1354, shortly after three, there was a solar eclipse, that lasted near half an hour.

Even when the date is one day wrong (this includes also the day of the week, 16 September 1354 was Tuesday), the eclipse is clearly the one on 17 September. It is not evident what the author means by "shortly after three". He seems to have confused the canonical hour hora tercia (about 9:00 am, when the eclipse really happened) with the three in the afternoon, maybe an error from the translation of an older and unknown source.

In the same section of the book there are only two other solar eclipses from the $\mathrm{XV}^{\text {th }}$ century and they both reached a magnitude of 0.98 or greater, so we can assume that the author wanted to remark a very special event and it is likely that the A.D.1354 eclipse had a similar magnitude in Barcelona.

Using the current astronomical data, the eclipse was partial in Barcelona, with maximum at 9:15am and a Sun's altitude of $26.8^{\circ}$

Let us focus now on the register from Sos, a small village sited in northern Spain. Its importance was remarkable up to the $\mathrm{XV}^{\text {th }}$ century, because it was very near of the frontier between the Kingdoms of Navarra and Aragon.

The reference to this eclipse was recently found ${ }^{8,22}$. The authors discovered a pair of inscriptions sited in the arc of middle point of the arcade overlooking the Council Square that have gone unnoticed.

It is documented that the old market was held under the portal of the Council Square. At the union of the inner arcs there is still the measure of the vara jaquesa and the niche to place the scale. 


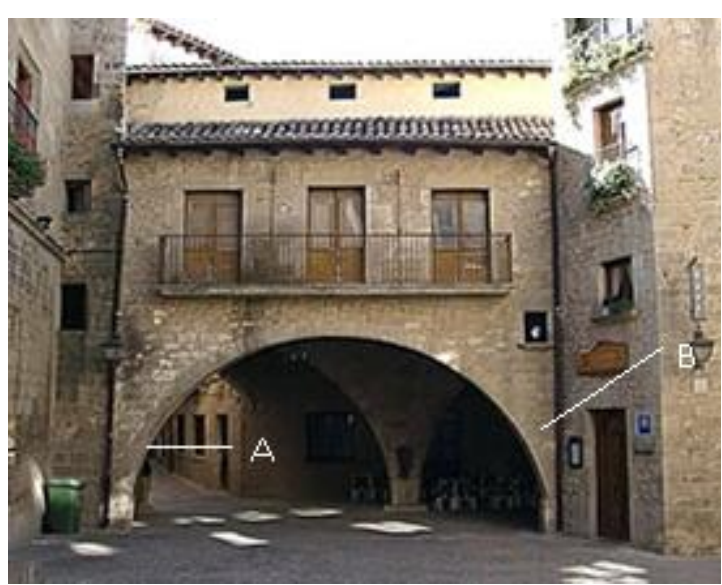

Figure 4: Portal of the Council Square of Sos with indications of the positions of the two inscriptions

The inscriptions were found on two separate ashlar stones: counting from the bottom, on the $7^{\text {th }}$ stone on the left (A) and the $8^{\text {th }}$ on the right (B), (see figure 4). The stones are turned though 180 degrees. We assume that the original position would be correct, but a dismantling and subsequent assembly of the arc has led them to their current orientation.

Inscription A states "Anno domini MCCC XXXIX", possibly the date of construction of the arch.

Inscription B (see figure 5) was harder to read. It is longer and more crudely engraved than inscription A, the space between the letters and the size of the engraving are irregular. The emblem of Aragon is clearly visible below in the left of the image, even with the piece rotated.

In order to read the inscription, editing and retouching the image was imperative. The engraving states: Anno domini MCCC: L: IIII XVII die septembris: hora prima: Obscura uit sol. The translation is:

In the first hour of 17 September in the year of God 1354 the Sun became dark.

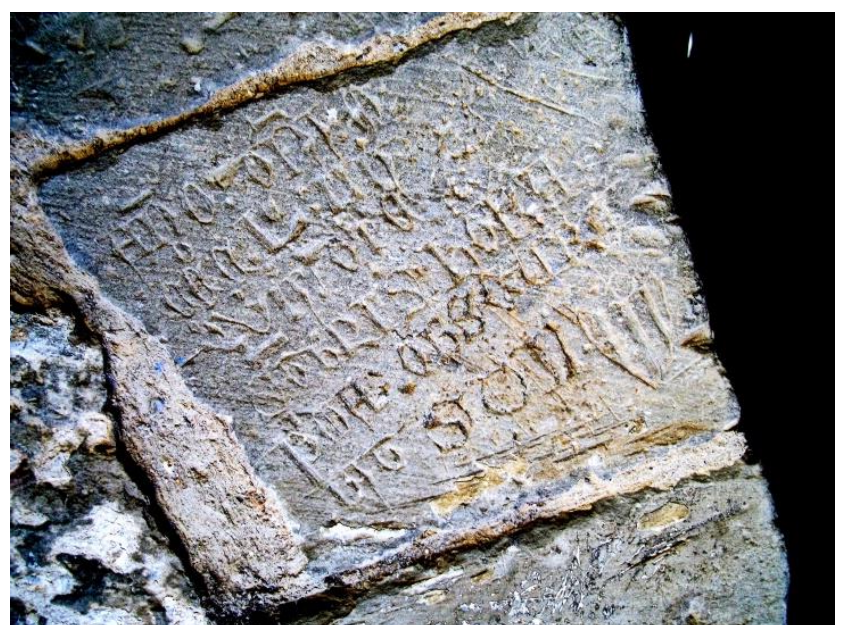

Figure 5: Inscription B (rotated $180^{\circ}$ ) with the report of the A.D.1354 solar eclipse. The emblem of Aragon is visible, on the lower right corner.

It is clear that we cannot claim totality from this report, but it is of interest to consider this possibility, mainly because the obtained range for $\Delta \mathrm{T}$ is very narrow, but also because there is a lack of other observations for this eclipse. An 
analysis of the band of totality of this eclipse using as a preliminary $\Delta \mathrm{T}$ value the one given by Stephenson for the epoch shows that the band of totality is very close to the city of Sos so, surely, if the eclipse was not total, it was nearly total.

In fact, using current astronomical parameters for the epoch, the eclipse turns out to be partial in Sos, reaching its maximum at 9:12 (the hora prima that, in this case, does not refer to the canonical hour). The Sun's altitude was $23.6^{\circ}$ and the estimated eclipse magnitude is more than 0.99 .

We are going to take into account different possible cases for this eclipse, including totality and 0.95 and 0.99 magnitude, in order to obtain more reliable ranges for the $\Delta \mathrm{T}$ parameter. From this observational site, we obtain a range of $200<\Delta \mathrm{T}<400$ s for totality, $-50<\Delta \mathrm{T}<600$ s for a magnitude of 0.99 and $-1100<\Delta \mathrm{T}<1950$ s for a magnitude of 0.95

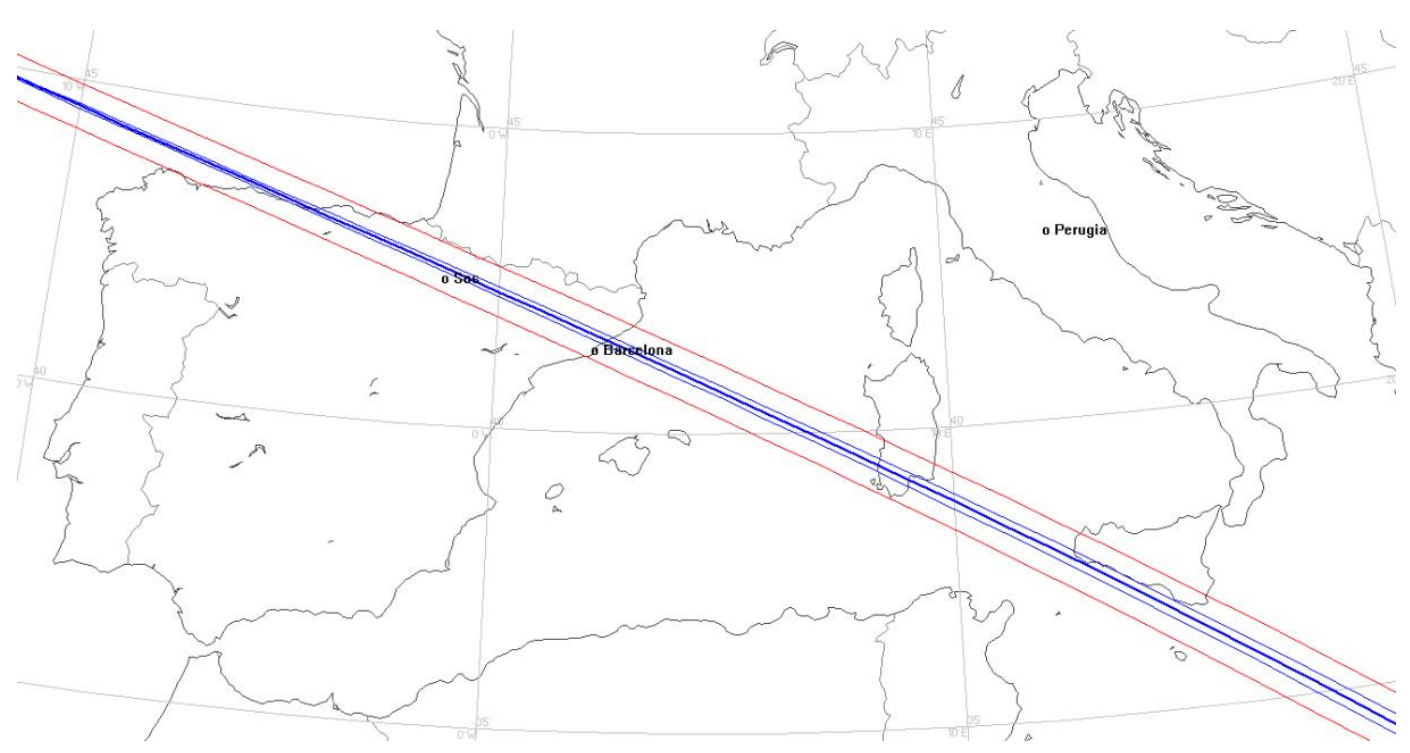

Figure 6: Path of totality for the eclipse of AD1354 September 17. The red band is the limit for a 0.99 magnitude. (Using SkyMap Pro ${ }^{29}$ )

4. $\Delta T$ from comparison among observational sites for the A.D.1239 and A.D.135 eclipses

The rotation of the Earth has been slowing down in the last centuries and considering the almost random effects of the sea tides, ice caps, earthquakes, liquid core, etc, the exact determination of the rate is a difficult problem to solve. The observations of ancient eclipses provide a straightforward way to determine both the variations in the spin of the Earth and the orbital motion of the Moon. formula:

An approximate solution for $\Delta \mathrm{T}$ (in seconds) may be obtained using the

$$
\Delta \mathrm{T}=240\left(\Lambda-\Lambda^{\circ}\right)
$$

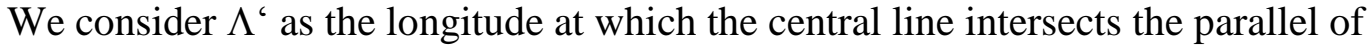
latitude passing through the site of the observation sited at longitude $\Lambda$ (both $\Lambda$ and $\Lambda^{\prime}$ in degrees). In practice, we can set upper and lower bounds for $\Delta \mathrm{T}$ considering the width of the zone of totality: when the southern edge of the umbra shadow reaches the site a minimum value of $\Delta \mathrm{T}$ will be provided and a maximum value will be given when the northern edge of totality leaves the site. 
All these computations assume that the only unknown is $\Delta \mathrm{T}$ itself, while other orbital parameters are known with precision. The method is further explained in Stephenson $^{30}$.

In table 2 we list the coordinates of the cities involved in the new observations of the two eclipses that we consider in this work. Following the usual conventions, northern latitudes and westerly longitudes are positive. An asterisk* next to the name of the city means that the A.D.1354 eclipse was observed from this site.

\begin{tabular}{|c|c|c|}
\hline Place & Latitude $(\mathrm{deg})$ & Longitude $(\mathrm{deg})$ \\
\hline Barcelona $(*)$ & 41.36 & -2.16 \\
\hline Cardeña & 42.30 & +3.60 \\
\hline Montpellier & 43.62 & -3.88 \\
\hline Pamplona & 42.82 & +1.65 \\
\hline Soria & 41.76 & +2.46 \\
\hline Sos $\left(^{*}\right)$ & 42.48 & +1.21 \\
\hline
\end{tabular}

Table 2: Geographic coordinates (in degrees) for the sites involved in the A.D.1239 and (*)A.D.1354 eclipses.

In Figure 7 we can see the ranges of $\Delta \mathrm{T}$ for the A.D.1239 June 3 eclipse considering totality in all the observational sites. The vertical lines represent the range of $\Delta \mathrm{T}$ for which totality at the place would occur. The * represents the value of $\Delta \mathrm{T}$ for which the central line of the eclipse crosses the parallel of the city. Notice that we have included the sites of Marola and Toledo only for information purposes, but we will avoid these values in further computations. At first sight, the best values are obtained in Coimbra, Cardeña and Soria, while the other places give unusual large intervals.

The eclipse of A.D.1239 is the only large eclipse in Soria in the XIII ${ }^{\text {th }}$ century and the only total eclipse occurring near the city until year 1415. In a first approximation we studied the shadow area taking as a preliminary value for $\Delta \mathrm{T}$ the one provided by Stephenson for the epoch. We saw that Soria was very near to the central axis of totality of the eclipse. However, we considered that this was not enough to assert that the eclipse was total at the place, so we studied the range of values of $\Delta \mathrm{T}$ for which this hypothesis would be met. We obtained a range of $-1100<\Delta \mathrm{T}<1600$ s for the totality of the eclipse. If the eclipse were not total, we obtain values for $\Delta \mathrm{T}$ that are contradictory with the values obtained from other places where totality is unquestionable. Similar conclusions are obtained for the case of Cardeña. It is precisely in this latter place where we find the lower limit for the interval of $\Delta \mathrm{T}$, that is significantly narrower than the previous range.

In Figure 7, the interval limited by the lines represents the intersection of the intervals of $\Delta \mathrm{T}$ for all the considered sites (with the exception of Toledo and Marola). The range obtained is $-570<\Delta \mathrm{T}<900 \mathrm{~s}$ and its mean value is $\Delta \mathrm{T}=634 \mathrm{~s}$. The current estimated $\Delta \mathrm{T}$ for the epoch is $629 \mathrm{~s}$. The range obtained by Stephenson considering his observational sites was $-500<\Delta \mathrm{T}<1450$. 


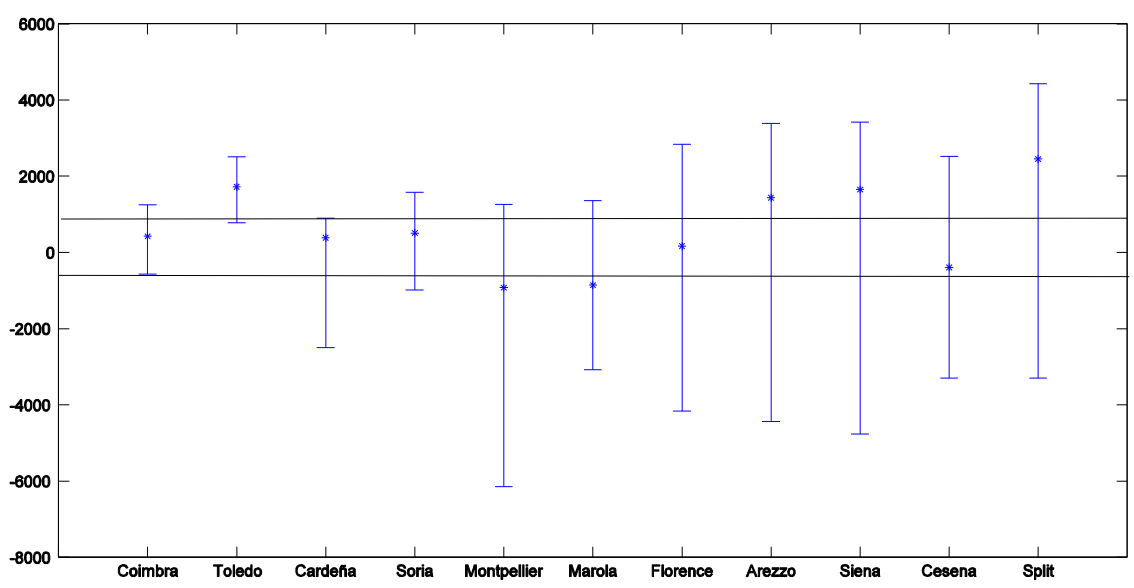

Figure 7: Values for $\Delta \mathrm{T}$ at each of the considered observational sites. The mean value for the $\Delta \mathrm{T}$ computed is 634s (excluding Toledo and Marola). The range marked by the two solid lines represents the common values for $\Delta \mathrm{T}$.

The case of the A.D.1354 eclipse is more sensitive. Totality cannot be asserted either for Sos or for Barcelona, but it seems quite plausible to consider a 0.99 magnitude for both sites. In this case, we obtain a range of $0<\Delta \mathrm{T}<650$ s for Barcelona and $-50<\Delta \mathrm{T}<600 \mathrm{~s}$ for Sos. The mean $\Delta \mathrm{T}$ value is $316 \mathrm{~s}$ while the current estimated value for the epoch is 392 s.

Regarding the comparison with the results provided by other authors, this is not an easy task, because the authors who have worked on this issue use eclipses far removed from the XIII and XIVth centuries (for example, Tanikawa et al. $^{31,32}$ deal only with eclipses up to the VIth century) or they study the eclipses from an historical point of view and do not provide numerical values for any astronomical parameters (see, for example $\mathrm{Liu}^{33}$ or Han Yan-Ben and Qi-Yuan Qiao $^{34}$ regarding to Asiatic eclipses and Mozzafari ${ }^{35}$ or Hamid-Reza Giahi Yazdi $^{36}$ regarding to Arab eclipses).

\section{Conclusions}

We have presented several previously unnoticed data for the A.D.1239 and A.D.1354 eclipses. We have paid great attention to the three stone engravings found in Soria and Sos.

In the study of the variation of the Earth rotation using untimed observations of total eclipses, the precision of the obtained values of $\Delta \mathrm{T}$ depends mainly on the width of the totality band and on the precise definition of the observational place. The analysis of an eclipse observed from multiple sites could provide, under certain conditions, a more precise measure for the former value. To this aim, the study of new data together with the conjunct determination of the parameters with other almost contemporary eclipses could provide a range of $\Delta \mathrm{T}$ and could help to identify redundant or inconsistent observations and places. 


\section{Acknowledgements:}

The authors would like to thank José Martínez Usó for his help in the images management, the Museo Numantino of Soria for allowing us the reproduction of Figure 2. Part of this work was supported by a grant AICO/2015/037 from Generalitat Valenciana

\section{References.}

1. F.R. Stephenson. Historical Eclipses and Earth's Rotation (Cambridge University Press, Cambridge 1997)

2. L.V. Morrison, F.R. Stephenson. "Historical values of the Earth's rotational clock error $\Delta \mathrm{T}$ and the calculation of eclipses", Journal for the History of Astronomy, xxxv (2004), 327-336

3. See Stephenson, op cit. (Ref 1)

4. J.K. Fotheringam. Monthly Notices of the Royal Astronomical Society. (1935) 95,719

5. R.R. Newton. Medieval Chronicles and the rotation of the Earth. Johns Hopskins University Press, (1972)

6. K. Tanikawa, M. Soma. Publications of the Astronomical Society of Japan, (2004) 56, 215

7. K. Tanikawa, T. Yamamoto, M. Soma, Publications of the Astronomical Society of Japan, (2004) 56, 779

8. E.M. Standish. JPL Planetary and Lunar ephemerides, DE405/LE405, (1998) IOM, 312. F-98-048

9. M. Chapront-Touze, J. Chapront. Astronomy and Astrophysics, (1988), 190, 342

10. F.R. Stephenson "Investigation of medieval European records of solar eclipses" Journal for the History of Astronomy, xli (2010) 95-104

11. See Stephenson, op cit. (Ref 1)

12. Celoria G. Sull'eclissi solare totale del 3 Giugno 1239. Memorie del reale instituto Lombardo de science e letteri, Classe di Scienze Matematiche e Naturali. 13, 275300,1877 .

13. See Newton, op cit. (Ref 5)

14. A. Ferrando, V.J. Escartí. "Llibre dels Fets" (Ed. Afers, Barcelona, 1995), (chap. 305)

15. See Stephenson, op cit. (Ref 1)

16. See Ferrando and Escartí, op cit. (Ref 14)

17. Können G.P., Hinz, C. "Visibility of stars, halos and rainbows during solar eclipses". Applied Optics, (2008), 47, 34 , H14

18. See Celoria, op cit. (Ref 13)

19. Monumenta Germaniae Historica, SS, T.25, 841

20. Berganza, Francisco de. Antigüedades de España, propugnadas en las noticias de sus reyes en la coronica del Real Monasterio de San Pedro de Cardeña. Parte Segunda. Madrid. 1721

21. Morán J. "Cronicó de Perpinyà (segle XIII): (estudi filofògic I lingüistic)", Publicacions de l'abadia de Montserrat. Barcelona. (1998)

22. J.M. Rodríguez (coord.), Enciclopedia del románico en Castilla y León. Fundación Santa María La Real. (2002)

23. Mariott, C.A., Sky Map Pro 11. http://www.skymap.com, 2005

24. See Stephenson, op cit. (Ref 1)

25. Ginzel F.K. Astronomische Untersuchung über Finsternisse. II Abhandlung. (Sitz.- Ber. Akad. D. Wiss.) Wien. 1882

26. Bruniquer E. G. Rúbriques de Bruniquer : Ceremonial dels magnifichs consellers y regiment de la Ciutat de Barcelona. Barcelona : Impr. d'Henrich, 1912-1916.

27. L. Ibañez, P. Dominguez. "Momentos en Sos". Ayuntamiento de Sos del Rey Católico. (2005), J. Torres, L. Ibañez. Boletin Arkeolan, (2004) 12, 103

28. Ibid.

29. See Mariott, op cit. (Ref 23)

30. See Stephenson, op cit. (Ref 1$)$

31. See Tanikawa, op cit. (Ref 6, 7)

32. Liu Ci-Yuan. An ancient solar eclipse record "Tian-da-yi" in the 10th century BC. Chin J. Astron. Astrophys. 2. 5. 391-395. 2002

33. Han Yan-Ben, Qiao Qi-Yuan. A check on the variations of earth's rotation with an ancient solar eclipse. Chin J. Astron. Astrophys. 3. 6. 569-575. 2003. 
34. Mozzafari S.M. Historical annular solar eclipses. Journal of the British Astronomical Society. 2013.

35. Hamid-Reza Giahi Yazdi_Al-Khwarizmi and annular solar eclipse. Arch. Hist. Exact. Sci. 2011. 